\title{
NEOLIBERALISMO COMO SIMBIOSE DE POLÍTICAS APARENTEMENTE CONTRADITÓRIAS: AS PENAIS-PUNITIVAS E AS DE FOMENTO AO EMPREENDEDORISMO '
}

\author{
Neoliberalism as a symbiosis of apparently contradictory policies: the penal- \\ punitive and the promotion of entrepreneurship
}

\author{
Rodrigo Gameiro Guimarães ${ }^{2}$ \\ Rosimeri Carvalho da Silva ${ }^{3}$
}

\begin{abstract}
Resumo
Este ensaio propõe uma articulação de abordagens teórico-históricas de crítica ao neoliberalismo. Esta proposta está sintetizada no argumento de que no Estado neoliberal se produz uma simbiose de políticas, aparentemente contraditórias. De um lado, as políticas de fomento ao empreendedorismo e de verniz liberal que reduzem a legislação de proteção ao trabalho e de garantia a direitos sociais, preservando o direito à propriedade privada e promovendo empresas, mercados e as capacidades empreendedoras individuais (entrepreneurfare). De outro lado, as políticas disciplinares-punitivas direcionadas aos que dependem dos serviços e benefícios sociais, que passam a ser condicionados à aceitação de trabalhos precários ou à assiduidade em treinamentos para geração de renda (workfare e entrepreneurfare) e, que aplicam, com mais intensidade, medidas de contenção penal e encarceramento (prisonfare) aos insubmissos a esse disciplinamento. Esse argumento é explicado nas seções do texto. A partir de Wacquant, mostramos a configuração das políticas sociais em políticas de disciplinamento para o trabalho e como as consequências sociais disso são respondidas sistematicamente por políticas punitivo-penais. E, para compreender as mudanças nas concepções econômicas que estão associadas às mudanças indicadas por Wacquant e implicaram em políticas de fomento ao empreendedorismo, recorremos à análise de Puello-Socarrás sobre deslocamentos ideológicos e teóricos no projeto neoliberal. Por fim, discutimos os principais fundamentos e contribuições da aproximação dessas duas abordagens de crítica ao neoliberalismo.
\end{abstract}

Palavras-chave: neoliberalismo; políticas públicas; Estado; empreendedorismo; encarceramento.

\footnotetext{
Abstract

This essay is an articulation of theoretical-historical critical approaches to neoliberalism. This proposal is summarized in the argument that the neoliberal state produces a symbiosis of policies, apparently

1 Os autores agradecem o apoio do CNPq - Conselho Nacional de Desenvolvimento Científico e Tecnológico e do PRODEP/UFAL - Programa de Desenvolvimento de Pessoal da Universidade Federal de Alagoas. Igualmente agradecemos a avaliação detalhada, criteriosa e construtiva realizada pelos avaliadores, os comentários foram essenciais para chegarmos nesta nova versão do texto.

2 Professor e Coordenador de Pesquisa e Pós-Graduação da FEAC/UFAL.Pesquisador do Núcleo de Estudos Marcelo Milano Falcão Vieira (NeMaVi) e do Grupo de Estudo em Dinâmicas Organizacionais (GEDO). E-mail: rgameiro@gmail.com Cidade: Maceió-AL.

3 Doutora em Administração. Professora da Universidade Federal do Rio Grande do Sul (UFRGS). Email: rosimeri.carvalho@ufrgs.br Cidade: Jouy-en-Josas - França.
} 
Neoliberalismo como simbiose de políticas aparentemente contraditórias: as penais-punitivas e as de fomento ao empreendedorismo | Rodrigo Gameiro Guimarães e Rosimeri Carvalho da Silva

contradictory. On the one hand, the policies to promote entrepreneurship and with liberal polish that reduce labor protection legislation and the guarantee of social rights to preserve the right to private property and promoting companies, markets and entrepreneurship (entrepreneurfare). On the other hand, the disciplinary-punitive policies were directed to those who depend on services and social benefits, which are conditioned to the acceptance of precarious work or attendance in training for income generation (workfare e entrepreneurfare), and which apply with more intensity containment measures punishment and imprisonment (prisonfare) to those who are disobedient to that discipline. This argument is explained in the sections of the text. Based on Wacquant, we show the configuration of social policies in disciplinary policies for work and how the social consequences of this are systematically answered by prison-based policies. And in order to understand the changes in economic conceptions that are associated with the changes indicated by Wacquant and implying in policies to foster entrepreneurship, we turn to Puello-Socarrás's analysis of ideological and theoretical shifts in the neoliberal project. Finally, we discuss the main foundations and contributions of the approximation of these two critical approaches to neoliberalism.

Keywords: neoliberalism, public policies; State; incarceration; entrepreneurship.

\section{O argumento...}

Propomos neste ensaio uma articulação de abordagens teóricohistóricas de crítica ao neoliberalismo, entendido como um acontecimento histórico dinâmico, constituído por programas políticos e teóricos em disputa que respondem a diferentes configurações espaço-temporais. Buscamos, entretanto nessas teorias algumas características genéticas e que, apesar de mutações, permitam distinguir e caracterizar o neoliberalismo, considerando suas transformações. Considerando o contexto social, então, identificamos no programa neoliberal tanto as politicas de fomento ao empreendedorismo quanto as de encarceramento em massa. Tais politicas dificilmente seriam qualificadas de neoliberais, porém há análises criticas que as qualificam como tal, ainda que não as associem de forma relacional, como propomos a seguir.

Argumentamos que há uma articulação entre essas políticas, pois no Estado neoliberal se produz a simbiose de politicas, aparentemente contraditórias. De um lado, as políticas de fomento ao empreendedorismo 
Neoliberalismo como simbiose de políticas aparentemente contraditórias: as penais-punitivas e as de fomento ao empreendedorismo | Rodrigo Gameiro Guimarães e Rosimeri Carvalho da Silva

e de verniz liberal que reduzem a legislação de proteção ao trabalho e de garantia a direitos sociais, preservando o direito à propriedade privada e promovendo empresas, mercados e as capacidades empreendedoras individuais (entrepreneurfare). De outro lado, as politicas disciplinarespunitivas direcionadas aos que dependem dos serviços e beneficios sociais, que passam a ser condicionados à aceitação de trabalhos precários (workfare) ou à assiduidade em treinamentos para geração de renda (entrepreneurfare) e, que aplicam, com mais intensidade, medidas de contenção penal e encarceramento (prisonfare) aos insubmissos a esse disciplinamento.

Adotamos o termo simbiose por considerar que essas políticas estão sob o mesmo programa neoliberal, mas não constituem uma síntese, ou seja, não compreendemos como uma fusão num todo coerente ou mesmo a união de partes separadas para formar uma nova. Apesar da aparente contradição, a liberdade de um lado e a punição de outro, igualmente não compreendemos que seja a síntese de partes contraditórias, pois como pretendemos mostrar a contradição está apenas na aparência. Do mesmo modo, não se trata de abigarramiento ou hibridização ${ }^{4}$, pois não estamos propondo que essas diferentes politicas componham uma coisa com elementos diversos e sem conexão ou sejam uma mistura para formar algo novo. Adotamos o termo simbiose como uma metáfora para explicar uma interação entre duas espécies de políticas que juntas no mesmo programa e, em associação, se beneficiam. Aliás, este é o principal propósito deste ensaio, sugerir como políticas de orientação distinta, e aparentemente contraditórias, podem compor o mesmo programa e, assim, se beneficiarem mutuamente e, principalmente, ao projeto neoliberal. Essa inspiração metafórica num conceito da biologia não implica em reduzir a realidade social e sua politicidade ao tratamento sistêmico e funcionalista que

4 Para uma discussão mais detalhada sobre a adoção desses termos, sugerimos a leitura de PUELLOSOCARRÁS, J.F. "Más allá del 'Gato-perro'. Hacia la Comparación en condiciones de abigarramiento", en: Lucca, JB, Peixoto de Olivera, R y Fernández de Lara Gaitán, A. (comps.) Desafíos democráticos latinoamericanos en perspectiva comparada. Rosario: Editorial de la Universidad Nacional de Rosario, pp. 162-201, 2017 e de outro texto mais seminal de TAPIA, Luis. El Estado en condiciones de abigarramiento. In: García Linera, Álvaro, Prada, Raúl, Tapia, Luis y Vega, Oscar. El Estado. Campo de Lucha. La Paz: CLACSO, p. 97-128, 2010. 
normalmente se faz ao adotar esses conceitos da biologia. Pelo contrário, tal metáfora não é o ponto de chegada se não que o ponto de partida para pensar a relação entre as políticas que, a princípio, seriam analisadas isoladamente dado o seu caráter aparentemente contraditório.

Nosso argumento é também uma contraposição à opinião comum, assim como a uma parcela da acadêmica, de que o neoliberalismo é um corpo ideológico homogêneo que defende a redução do tamanho do Estado (via reformas e privatizações) e da sua mínima intervenção na economia para possibilitar um mercado autorregulável e a livre iniciativa individual. Defendemos a compreensão do neoliberalismo como um acontecimento mais complexo em que o Estado é a pedra angular e um objeto de disputas, uma vez que tem o papel de preservar uma estrutura institucional como suporte a sólidos direitos à propriedade privada e ao livre mercado e que garantiria a construção do bem estar humano pela promoção das liberdades e capacidades empreendedoras individuais, tal como definem as teorias das práticas político-econômicas neoliberais, de acordo com Harvey (2013, p. 12).

Nesse sentido, para Harvey (2013), o Estado neoliberal garante a segurança monetária, cria mercados e, se necessário, usa os aparatos de defesa, de polícia e as leis, ou até a força, para garantir o funcionamento dos mercados. Dessa forma, ele atribui ao Estado uma positividade, ou figura construtora do regime neoliberal, apontando as implicações do neoliberalismo como ataque aos direitos trabalhistas (pela afronta ao poder dos sindicatos) e flexibilização dos direitos sociais básicos. Os bens comuns tornam-se produtos de mercado, assim como a segurança individual, de modo que o bem-estar corporativo toma o lugar do bem-estar social. Essas transformações não acontecem sem resistências ou contradições, para Harvey (2013, p. 80) há um paradoxo das intensas intervenções estatais que, ao não darem certo, levam o Estado a recorrer à força bruta e ao poder de polícia para suprimir as oposições neoliberais, de modo que "A liberdade das 
Neoliberalismo como simbiose de políticas aparentemente contraditórias: as penais-punitivas e as de fomento ao empreendedorismo | Rodrigo Gameiro Guimarães e Rosimeri Carvalho da Silva

massas teria de ser restringida em beneficio das liberdades dos poucos". Lembramos que Harvey (2005, p. 80), a partir de Marx e Engels, define que o Estado se origina da contradição dos interesses particulares e os da comunidade, como também da necessidade de manter os antagonismos de classe sob controle, e é resultado da criação humana para sua própria dominação.

Apesar de não partir da mesma noção de Harvey, para compreender o Estado como uma forma de dominação, nos guiamos pela definição de Bourdieu (1996, p. 97-8), pois ele é uma das principais referências das ideias que orientam o argumento deste texto e por seu amplo conjunto de pesquisas sobre dominação. Ele sugere que não se pode tratá-lo como um ente homogêneo, mas em contradição, o Estado é uma incógnita que “[...] reivindica com sucesso o monopólio do uso legítimo da violência física e simbólica em um território determinado e sobre o conjunto da população correspondente [...] a instituição instituída faz com que se esqueça de uma longa série de atos de instituição e apresenta-se com toda aparência do natural." Essa concepção do Estado em Bourdieu (2014, p. 145), como lugar de antagonismos, enfatiza que há uma ambiguidade fundamental do processo de gênese e do próprio Estado, caracterizando que, “[...] O Estado é de tal forma um Jano que não se pode enunciar uma propriedade positiva sem enunciar simultaneamente uma propriedade negativa [...] Descrever a gênese do Estado é descrever a gênese de um campo social [...]". Uma ilustração desse princípio do efeito Jano pode ser vista nas pessoas que entram no jogo político e têm acesso a posições em que se pode falar em nome de todos, do bem público e do que é bom para o público e ao mesmo tempo se apropriam disso, assim esse privilégio do universal só é conseguido por aqueles que ao mesmo tempo monopolizam o universal. Logo, a gênese do Estado é "[...] no fundo, inseparável da constituição de um monopólio do universal, sendo a cultura o exemplo por excelência.”. E, ainda, “[...] é a gênese de um lugar de gestão do universal, e ao mesmo tempo de um monopólio do universal, e de um conjunto de agentes que participam do 
monopólio de fato dessa coisa que, por definição, é o universal” (BOURDIEU, 2014, p. 147-149).

Wacquant (2012, p. 511) destaca que o Estado, na concepção de Bourdieu, não é um corpo homogêneo, ator coerente (mesmo que opere autonomamente ou como servo dos dominantes), nem é alavanca única. Ao defini-lo como um campo, considera que é um espaço de lutas e forças sobre fronteiras, responsabilidades e prioridades da autoridade pública, ou seja, sobre os "problemas sociais". Ele enfatiza que Bourdieu define que o Estado é atravessado por duas batalhas internas, a vertical (dominantes $\mathrm{x}$ dominados) que opõe a alta nobreza do Estado, dos formuladores de politicas neoliberais que fomentam a 'mercantização', à "baixa nobreza estatal”, dos executores que defendem os objetivos protetores da burocracia pública; e a batalha horizontal (entre as modalidades de capital o econômico e o cultural) entre a mão direita do Estado, a ala econômica com as imposições fiscais e disciplina de mercado, e a mão esquerda ou ala social que protege os desprovidos de capitais econômicos e culturais (WACQUANT, 2012).

Aclarada a concepção de Estado que nos orienta, voltamos ao neoliberalismo. E nos questionamos: como trazer um levantamento teórico de um tema tão amplamente debatido pelo menos há duas décadas? Adotamos, então, como critério inicial selecionar textos que tomam o neoliberalismo como objeto principal de análise (tais como Harvey, 2013; Puello-Socarrás, 2008a; Duménil e Levy, 2014; Laval e Dardot, 2013). Alguns destes autores nos foram sugeridos pelo trabalho de Wacquant (2012, p. 509), que faz uma espécie de meta-análise dessas críticas ao neoliberalismo e propõe outra abordagem, definida por ele como uma "via média" entre os dois polos que caracterizou. Em um polo, Wacquant (2012) sugere que está a concepção hegemônica neoliberal, ancorada em variantes de domínio de mercado (neoclássicas e neomarxistas) e abordada pelas implicações econômicas mais amplas como a financeirização e a desregulamentação da economia (uma ilustração seria Duménil e Lévy, 
Neoliberalismo como simbiose de políticas aparentemente contraditórias: as penais-punitivas e as de fomento ao empreendedorismo | Rodrigo Gameiro Guimarães e Rosimeri Carvalho da Silva

2014); e no outro estão aquelas alimentadas por derivações da noção

foucaultiana de governamentalidade que definem a neoliberalização como um fenômeno não só econômico, mas como uma racionalidade politica (FOUCAULT, 2008; DARDOT e LAVAL, 2013).

A primeira abordagem é criticada por Wacquant (2012, p. 507) por ser excessivamente restrita e apologética ao tomar o discurso neoliberal em seu valor nominal, bem como defini-lo a partir da imposição direta da economia neoclássica e do mercado como mecanismo ideal. Essa concepção está bem estabelecida e designa o império do capital que impõe ditames de mercado não só a todos os territórios, mas também às atividades humanas, associa assim o neoliberalismo a visão de mercado autorregulador e o Estado antagônico a ele, como obstáculo à eficiência. Nesse sentido o consenso neoliberal inclui o abandono de políticas keynesianas, e esvaziamento do Estado e privatização de suas funções. Ele cita inclusive que, em Harvey5 ${ }^{5}$ o Estado só se distanciaria da lógica de governo mínimo para fomentar os negócios, instituições financeiras e reprimir a resistência popular ao ímpeto neoliberal da acumulação por espoliação, ou seja, define em geral o neoliberalismo como uma retração do Estado síncrona à expansão do mercado (WACQUANT, 2012, p. 508).

Não nos parece bem enquadrada a interpretação que faz Wacquant (2012) do trabalho de Harvey (2013), pois, como indicamos, Harvey vai além de uma análise do discurso neoliberal em sua forma nominal ou de considerá-lo uma ampliação da economia neoclássica. Ele constrói uma história analítica e político-econômica do neoliberalismo, não estritamente econômica, mas muito atenta às implicações sociais, sobretudo com suas contradições políticas e em relação ao desenho do Estado.

No entanto, na construção da sua crítica ao neoliberalismo, Wacquant (2014) não se restringiu ao exame de outras abordagens críticas ao neoliberalismo, pois desenvolveu pesquisas de campo que investigam as implicações do projeto neoliberal no mundo concreto e na vida cotidiana. Nelas constatou que, com algumas exceções (Alemanha, Áustria, Canadá e

5 O mesmo livro que referenciamos neste texto, mas a versão citada foi a inglesa, publicada em 2005. 
Neoliberalismo como simbiose de políticas aparentemente contraditórias: as penais-punitivas e as de fomento ao empreendedorismo | Rodrigo Gameiro Guimarães e Rosimeri Carvalho da Silva

Grande parte da Escandinávia), o encarceramento cresceu nas sociedades ocidentais, incluindo nações com governos pós-autoritários da América Latina e do bloco soviético. Analisou que isso aconteceu à medida que essas sociedades faziam a transição para a economia de mercado, precarizavam o trabalho e transformavam suas politicas sociais de bem-estar em politicas que condicionavam a renda mínima a certas obrigações como a formação profissional ou aceitação do emprego precário (workfareø). Nesse contexto, identifica essas transformações junto à reativação da face punitivo-penal do Estado como uma medida para administrar populações pobres e marginalizadas, explicando o crescimento desmedido dos aprisionamentos nesses países (WACQUANT, 2012).

Wacquant (2012, p. 509-10) propõe uma abordagem ao neoliberalismo transversal às perspectivas econômica e da racionalidade, pois considera que o neoliberalismo é um projeto aberto, plural e mutável, mas defende que há um núcleo genético (institucional) que "[...] o torna distinto e reconhecivel. Esse núcleo consiste numa articulação entre Estado, mercado e cidadania que aparelha o primeiro para impor a marca do segundo à terceira.”. A definição desse núcleo, seria uma exigência lógica, pois mesmo considerando que há diversos tipos e espécies locais de neoliberalismo, eles surgiram de mutações, assim os neoliberalismos pressupõem um Neoliberalismo, ou seja, um gênero comum do qual derivem. Assim, "[...] toda e qualquer ocorrência periférica e parcial do fenômeno só poderá ser caracterizada como tal em referência, aberta ou encoberta, a um núcleo original mais completo." (WACQUANT, 2012, p. 509-10), a que chamamos de características genéticas. Dentre essas características genéticas das políticas neoliberais, Wacquant aponta as transformações das

\footnotetext{
6 O termo workfare é adotado por Wacquant (2012) para caracterizar programas assistenciais voltados aos pobres que vinculam condicionalmente o recebimento do auxílio como beneficio pessoal em detrimento da aceitação de trabalhos mal remunerados ou de formações profissionais orientadas para o emprego. Esse termo também é adotado por outros pesquisadores, como Jamie Peck e Bob Jessop, que analisam as politicas econômicas e sociais que se constituem após a crise do período keynesiano e de bem-estar. Peck denomina como reformas do bem-estar em imposição do trabalho ou políticas de bem-estar para o trabalho, treinamento e empregabilidade, enquanto Jessop considera que essas políticas estão relacionadas a reformas econômicas com base num referencial schumpeteriano.
} 
Neoliberalismo como simbiose de políticas aparentemente contraditórias: as penais-punitivas e as de fomento ao empreendedorismo | Rodrigo Gameiro Guimarães e Rosimeri Carvalho da Silva

politicas sociais de bem-estar em politicas de disciplinamento, acompanhadas da ampliação das penais-punitivas, que caracteriza como prisonfare.

Ao mesmo tempo que vemos recrudescer a face punitivo-penal do Estado, também assistimos politicas neoliberais que se propõem a ampliar a liberdade do trabalhador ao flexibilizar os direitos trabalhistas e incentivar a livre iniciativa do empreendimento. Nesse sentido, identificamos nas teorias de crítica ao neoliberalismo um diagnóstico comum acerca da definição de ser humano das teorias econômicas, que não é enfatizado em todas, mas merece destaque pela sua recorrência.

Wacquant (2012) assinala a ascensão do discurso da responsabilidade individual ou de um individualismo moralizante, associado ao império da mercadoria, em que inclusive as causas da insegurança social e econômica são atribuídas individualmente aos habitantes de zonas marginalizadas e a pobreza é convertida em responsabilidade individual (WACQUANT, 2013). De outra forma, Harvey (2013) explica que no neoliberalismo o bem-estar é associado com a garantia das liberdades individuais e capacidades empreendedoras.

Por outra abordagem, Foucault (2008) caracteriza a sociedade neoliberal por ser guiada pela concorrência, não como grande mercado, mas como uma sociedade empresarial onde se reconstitui o homo oeconomicus, não o da troca, mas o da empresa e da produção, pois as correntes econômicas neoliberais defendem que $\mathbf{o}$ individuo se torne mais enterprising, empresário de si, revisando a concepção clássica de homem das ciências econômicas. Nessa linha, Dardot e Laval (2016, p. 26-7) destacam que a mudança importante do neoliberalismo, em relação ao liberalismo clássico, foi valorizar a concorrência ${ }^{7}$ e a empresa como forma

\footnotetext{
7 Esses autores definem concorrência diferentemente da visão da economia clássica, porque consideram que ela se estabelece entre desiguais. Concordamos em parte com essa tese da generalização da concorrência (entre desiguais) como principio ou norma que rege a relação dos individuos, ou seja, da competição entre indivíduos, como por exemplo no mercado de trabalho, porque, como nos mostra Harvey (2005), sob o neoliberalismo há uma tendência do estabelecimento de uma competição monopolista que leva a processos de oligopolização em diversos mercados, inclusive com suporte do Estado. Ainda que concordemos com Harvey $(2005$, p. 187) quando destaca que Marx considerou que "[...] a competição é, inevitavelmente, a "viga mestra" das relações sociais
} 
Neoliberalismo como simbiose de políticas aparentemente contraditórias: as penais-punitivas e as de fomento ao empreendedorismo | Rodrigo Gameiro Guimarães e Rosimeri Carvalho da Silva

geral de sociedade e modo de governo neoliberal em que "[...] se constrói na concorrência geral certa dimensão do homem, o entrepreneurship, que é o princípio de conduta potencialmente universal mais essencial à ordem capitalista [...]" e tal dimensão antropológica do homem-empresa é a principal contribuição dessa corrente (DARDOT E LAVAL, 2016, p. 134-5).

Puello-Socarrás aprofunda e expande as discussões sobre esta dimensão antropológica, buscando as origens disso nas teorias social e econômica que fundamentam o projeto neoliberal. Ao investigar as transformações internas aos paradigmas econômicos que fundamentam o ideário e as políticas neoliberais, Puello-Socarrás identifica que a noção de empreendedor ganha centralidade em relação à noção clássica de homem econômico, definindo a constituição de um Novo Neoliberalismo (PUELLOSOCARRÁS, 2008a, 2008b, 2010, 2013a, 2013b). Esse novo é caracterizado pelo trânsito de uma versão econômica ortodoxa para uma heterodoxa, mais influenciada pela versão austro-americana ${ }^{8}$, que desloca a importância de categorias como homo economicus, engenharia social, modelos de concorrência perfeita e equilíbrio e enfatiza noções mais funcionais como homem empreendedor (ou empresário de si para Foucault), empreendimento e racionalidade criativa, assim como novas formas de ação institucional (privatizações implícitas nas alianças público-privadas e quasemercados) que moldam o Estado e as politicas públicas (PUELLOSOCARRÁS, 2013b).

Identificamos em comum nessas críticas o diagnóstico de que o neoliberalismo mantém uma defesa da liberdade e da responsabilidade individual efetivada, no entanto, por um Estado que garante certa concorrência, a constituição de empresas e fomenta o desenvolvimento de

\footnotetext{
capitalistas em qualquer sociedade em que a circulação do capital é uma força hegemônica. As coercitivas leis da concorrência impõem aos agentes individuais ou coletivos (empresas capitalistas, instituições financeiras, Estados, cidades) certas configurações de atividades, que são, por si próprias, constitutivas da dinâmica capitalista. No entanto, a "imposição" acontece depois da ação e não antes. [...]”, ou seja, a imposição da competição só acontece depois da ação dos agentes, inclusive do Estado, definindo que a concorrência seja moldada, por exemplo, por políticas públicas.

8 Essa aspecto será tratado mais detalhadamente no seção 3 do trabalho.
} 
Neoliberalismo como simbiose de políticas aparentemente contraditórias: as penais-punitivas e as de fomento ao empreendedorismo | Rodrigo Gameiro Guimarães e Rosimeri Carvalho da Silva

capacidades empreendedoras nos indivíduos. Dessa constatação, adicionamos a suposição teórica de que o outro aspecto genético ao projeto neoliberal é naturalizado na relação social empreendedora que sustenta e é suportada pelo Estado capitalista neoliberal contemporâneo, denominado de

\section{entrepreneurfare.}

Esse conceito foi cunhado, em outro trabalho, a partir da crítica às conceituações que concedem ao Estado capitalista contemporâneo a atribuição de agente (empreendedor) incentivador ou criador de mercados (Mazzucatto; Musacchio e Lazzarini) e a outras que constatam mudanças e não uma redução nas formas de regulação do Estado neoliberal (Jessop; Peck; Rezende). A inspiração dessa crítica está apoiada no trabalho de Bourdieu (2006) sobre como na transformação da política social de habitação na França, o Estado foi um dos principais agentes, não só de regulação, mas de construção do mercado da casa.

Definimos provisoriamente entrepreneurfare como um conjunto de politicas, mecanismos regulatórios e legais que fazem do Estado neoliberal um agente investidor (acionista), credor e empreendedor cuja ação colabora com a criação ou reconfiguração de certos mercados e, por outro lado, um agente incentivador da qualificação e da formação de indivíduos empreendedores adaptados às transformações tecnológicas e econômicas e a flexibilização das leis trabalhistas, legalizando e naturalizando situações informais e precárias de trabalho (triviais nas economias periféricas). Historicamente, o componente entrepreneurfare do Estado neoliberal é uma contraparte tanto da retração dos regimes de seguridade social de caráter universalizante e coletivista, característicos dos Estados de Bem-Estar (welfare), como das políticas econômicas de orientação keynesiana e nacional-desenvolvimentistas. Igualmente, articula-se às politicas sociais que vinculam os auxilios a obrigações de trabalho (workfare) ou programas de transferência de renda focalizados na pobreza extrema, contribuindo na essência para o processo de precarização do trabalho e suas consequências sociais. Então, as politicas entrepreneurfare seriam, ao mesmo tempo, na aparência uma resposta às críticas sobre o recrudescimento disciplinador, 
punitivo e penal das politicas dos Estados neoliberais da América Latina, desde as ditaduras, postas como alternativa para tratar a pobreza e as desigualdades; e na essência geradoras dessas consequências que as politicas punitivo-penais no neoliberalismo para tratar.

Reconhecemos que termos discutidos (welfare, workfare e prisonfare), acrescidos do entrepreneurfare, se configuram como estruturas estruturantes resultantes das batalhas internas travadas no campo burocrático (Estado) e constituem formas históricas a partir das quais as ações e políticas públicas são constituídas e constituintes dessas formas. No entanto, esclarecemos que nosso objeto de investigação é a simbiose das politicas e não propriamente daqueles elementos estruturais do regime estatal. Ainda que essas dimensões sejam quase inseparáveis no plano concreto, a análise desses outros elementos nos levaria a realizar uma discussão teórica mais focada no Estado, na formação da agenda e nos mecanismos de produção das políticas, como pretendemos fazer em outro trabalho, do que numa análise das políticas públicas e suas consequências sociais.

Assim, na seção seguinte, detalhamos as análises de Wacquant sobre as politicas públicas, suas consequências e relações, destacando as de caráter prisonfare. No entanto, Wacquant não considera as mudanças nas concepções econômicas que orientaram as modificações nas políticas sociais e na regulação do mercado de trabalho, o que consideramos uma fenda na sua construção teórica, por isso propomos colmatar, na seção 3, com a construção teórica de Puello-Socarrás. Esse autor analisa como as teorias econômicas norteadoras do projeto neoliberal foram mudando, sem transformar sua essência, para responder às crises sociais decorrentes da implementação das politicas neoliberais. Ele não reduz, no entanto, o neoliberalismo a uma teoria ou análise econômica, pelo contrário considera que o neoliberalismo funciona como uma totalidade. Na última seção (4), resgatamos os principais pontos de aproximação das análises dos dois 
Neoliberalismo como simbiose de políticas aparentemente contraditórias: as penais-punitivas e as de fomento ao empreendedorismo | Rodrigo Gameiro Guimarães e Rosimeri Carvalho da Silva

autores que guiaram cada uma das partes anteriores e destacamos como a articulação entre elas, proposta no argumento deste ensaio, possibilita aprofundar a crítica ao neoliberalismo, mostrando que a aparente liberdade produzida pelas políticas de incentivo ao empreendimento tem como contrapartida o recrudescimento de politicas punitivo-penais.

\section{Reconfiguração das políticas sociais, a onda penal-punitiva e o estado-centauro}

Não é coincidência que a ideologia ${ }^{9}$ do mercado total e a retração da atuação social do Estado dirigidas pelas elites estadunidenses ocorreram pari passu com a ampliação das políticas de segurança circunscritas à dimensão criminal, afirma Wacquant (1999). Na sociedade neoliberal, as instituições policiais e penitenciárias reafirmam a autoridade de um Estado que é caracterizado pela impotência econômica, relega ao novo proletariado condições de trabalho precário como norma e isola os inúteis e indesejáveis que perturbam a ordem social (WACQUANT, 1999). A gestão carcerária e judicial da pobreza é mais provável e intensa quanto mais as politicas econômicas e sociais de um país "[...] inspire[m]-se em teorias neoliberais que levam à "mercantilização" das relações sociais, e quanto menos protetor desde o início seja o Estado-providência em questão.” (WACQUANT, 1999, p. 92). Entendemos que essa ideologia do mercado total ou da liberdade de mercado é inspiração somente ao redesenho das políticas sociais, pois o mesmo não acontece em relação às politicas econômicas que financiam atividades de incentivo às empresas e ao crescimento dos mercados e negócios.

Analisando as transformações nos EUA como um laboratório de ideias neoliberais, Wacquant (1999; 2013) identificou que a reforma da assistência social neste país - suprimiu o direito à assistência que provia materialmente os pobres e não eliminou a função moral do Estado - foi uma

\footnotetext{
${ }^{9}$ Ainda que Wacquant não tenha definido, nos textos citados neste artigo, o conceito de ideologia, Bourdieu (2001), sua principal inspiração, sustenta que as ideologias servem aos interesses particulares se apresentando como interesses universais, devendo a sua estrutura e suas funções às suas condições sociais de produção e circulação, elas seriam duplamente determinadas, ou seja, suas características devem aos interesses das classes ou frações de classe que elas exprimem como também aos interesses específicos dos que as produzem.
} 
espécie de transição do welfare state para o workfare que institui o assalariamento forçado como única alternativa de sobrevivência, justificada por colocar os indigentes no caminho da independência, só que em condições que ferem o direito social e trabalhista das pessoas dependentes das ajudas do Estado (WACQUANT, 1999, 2013). Essa mudança nunca pretendeu proteger os pobres, mas os obriga "[...] a preencher os interstícios periféricos do mercado de trabalho desregulamentado." (WACQUANT, 2013, p. 181-2).

Essa transição de politicas de welfare para workfare seria justificada como o preço para atingir mais eficiência e sucesso na competição capitalista que varria o globo, prometendo que os pobres seriam beneficiados por essa inovação politica, pois ela ampliaria as possibilidades de emprego. No entanto, o encolhimento das politicas de assistência social, convertidas em workfare nos EUA, não é uma resposta a mudanças econômicas, mas o exercício de governo direcionado a produzir e a adaptar-se a essas mudanças associadas à decomposição do proletariado urbano (WACQUANT, 2013). Tal decomposição do proletariado é explicada, em parte, pelo processo de expansão do emprego contingente que não tem decorrência cíclica ou conjuntural, pois pode ser observada em período de recuperação econômica, nem está somente relacionada à mudança na tecnologia e na gestão das empresas, pois é “[...] resultado de uma nova estratégia patronal de externalização da mão-de-obra e de seus custos, estratégia encorajada pelos poderes públicos e eficientemente forçada pelo marketing ativo das agências de emprego temporário. [...]" (WACQUANT, 2013, p. 106).

Identificamos que nessa crítica de Wacquant ao neoliberalismo há uma importante conexão apresentada na sua análise entre a mudanças nas politicas sociais para o disciplinamento e o consequente empobrecimento e marginalização da classe trabalhadora, afetada sobremaneira pela precarização do trabalho. Por outro lado, há uma certa ingenuidade, quiçá a romantização, na análise do Estado e políticas de Bem-Estar, das políticas 
Neoliberalismo como simbiose de políticas aparentemente contraditórias: as penais-punitivas e as de fomento ao empreendedorismo | Rodrigo Gameiro Guimarães e Rosimeri Carvalho da Silva

keynesianas e do pleno-emprego nos moldes fordistas que são superadas em Harvey e em Puello-Socarrás quando indicam o gene liberal dessas políticas. Além dessas, é preciso trazer a crítica de Lessa (2013) ao Estado de BemEstar que descortina não só a questão econômica, mostrando que a principal política dos 30 anos dourados foi investir no complexo industrial militar e em politicas públicas que aumentaram a lucratividade. Apesar disso, Lessa (2013, p. 175) lembra que normalmente o Estado de Bem-Estar é definido como “[...] o Estado que, por inspiração keynesiana, ampliou-se para abrigar em seu interior as necessidades dos trabalhadores [...] se caracterizaria por uma nova modalidade, mais humana e mais ética, de intervenção estatal na economia com a utilização em larga escala de políticas públicas voltadas aos mais carentes [...]". Por essa definição, exemplos típicos seriam a Alemanha Nazista e a União Soviética, onde as políticas públicas foram executadas com universalidade e generalidade, com programas de geração de empregos, de educação, de aposentadorias, de moradias etc., incomparáveis ao New Deal ou governo da França e da Inglaterra (LESSA, 2013, p. 175).

Lessa avalia que a constatação das contradições históricas nas caracterizações do Estado de Bem-Estar, que foram feitas a partir das politicas públicas implementadas, levou à tentativa de caracterizá-lo por ser um Estado democrático, regidos por economia livre e pós-segunda guerra. Para ele, isto não resolveu a fragilidade das definições. Ele mostra inclusive (LESSA, 2013, p. 142) que não houve ruptura na evolução da relação do Estado com a sociedade no pós-2 $2^{\text {a }}$ Guerra, pois as necessidades de reprodução do capital fizeram o Estado democrático promover tortura, exploração e cooptação da aristocracia operária.

O Estado de Bem-Estar não pode ser considerado um conceito, já que assume diferentes conteúdos dependendo do autor e do contexto, que serve para capturar as "mais traiçoeiras ilusões dos anos dourados" (LESSA, 2013, p. 182-3). Então, para Lessa (2013, p. 214), o Estado de Bem-Estar é um mito que "[...] fundamenta a "crença" (pois não é mais do que isso, uma crença) na capacidade de o Estado, pelas políticas públicas, mitigar ou superar as misérias contemporâneas." Esse mito permitiu “[...] que se cale 
sobre o caráter de classe das políticas sociais, sobre como elas servem para uma maior exploração dos trabalhadores e, ainda, possibilita "esquecer" o caráter imperialista dos Estados de Bem-Estar." (LESSA, 2013, p. 214).

A despeito dessa crítica, não se invalida toda a análise de Wacquant (2013), principalmente porque mostra a relação entre as políticas de workfare com a precarização do trabalho e acompanhadas intimamente pela difusão da penalidade punitiva e do encarceramento. "Em outras palavras, como a sua contrapartida 'prisional', a revolução do workfare é um projeto especificamente político, destinado a refazer não somente o mercado, mas também, e acima de tudo, o próprio Estado" (WACQUANT, 2013, p. 184). Não por acaso os EUA se tornaram "superpunitivos", depois de meados dos anos 70. Na América Latina, o Chile se tornou o principal encarcerador no início dos anos 80 e o Reino Unido foi a locomotiva penal da Europa dos anos 90 (WACQUANT, 2012, p. 514).

Esse endurecimento das politicas penitenciárias, judiciárias e policiais das últimas duas décadas é, para Wacquant (2013), parte de uma Triplice transformação do Estado definida pela redução do seu braço econômico ${ }^{10}$ junto à retração do social e expansão do punho penal. A mão invisível do mercado sobre o trabalho desqualificado é ampliada ideologicamente e complementada institucionalmente pelo punho de ferro do Estado penal. A regulação das classes populares pela "mão esquerda" do Estado (de proteção social, direito ao trabalho, educação, saúde, assistência social e moradia), conforme Bourdieu, é suplantada e suplementada pela regulação da "mão direita" que administra a polícia, a justiça e a prisão (WACQUANT, 2013). Este é um regime liberal-paternalista, segundo Wacquant (2013), caracterizado como: permissivo no topo, das classes superiores e corporações, e paternalista e autoritário na base, aqueles que se encontram entre a reestruturação do emprego e diminuição da proteção

\footnotetext{
${ }^{10}$ Wacquant trabalha com a ideia de braço econômico do Estado que atua sobre as classes populares, por isso muito voltado a políticas de emprego, diferente da visão tradicional que considera a influência econômica do Estado como uma intervenção no mercado como um todo.
} 
Neoliberalismo como simbiose de políticas aparentemente contraditórias: as penais-punitivas e as de fomento ao empreendedorismo | Rodrigo Gameiro Guimarães e Rosimeri Carvalho da Silva

social ou sua conversão como instrumento de vigilância e disciplinamento. Tal regime implica na configuração e é constituído por um outro tipo de Estado, o Centauro, que é

guiado por uma cabeça liberal, montada num corpo autoritário, aplica a doutrina do laissez faire et laissez-passer a montante, em relação às desigualdades sociais, aos mecanismos que as geram (o livre jogo do capital, desrespeito do direito do trabalho e desregulamentação do emprego, retração ou remoção das proteções coletivas), mas mostra-se brutalmente paternalista e punitivo a jusante, quando se trata de administrar suas consequências no nivel cotidiano (WACQUANT, 2013, p. 88).

Da construção desse Estado-Centauro participa o dispositivo político "liberal-paternalista" em ascensão que regulamenta os pobres duplamente pelo workfare disciplinar e pelo prisonfare neutralizador (WACQUANT, 2014). O prisonfare é um dos principais componentes desse dispositivo, e em analogia ao welfare, é definido como uma rede de politicas, agências, programas e discursos que propõem resolver os problemas urbanos pelo braço judicial do Estado em detrimento dos serviços sociais e de atendimento aos direitos humanos. É a generalização da contenção punitiva como uma técnica para governar as categorias marginalizadas (WACQUANT, 2014, p. 155).

Ao relacionar as transformações nas politicas econômicas, sociais e penais, Wacquant (2014) constrói um programa de pesquisa sobre a regulação da pobreza, a (de)formação do precariado pós-industrial e a antropologia histórica do Leviatã neoliberal, que visa

repensar o neoliberalismo como um projeto politico transnacional, uma verdadeira "revolução pelo alto" que não pode ser reduzida ao império nu do mercado (como sustentam tanto seus opositores quanto seus partidários), mas que engloba, necessariamente, os meios institucionais requeridos para fazer advir esse império: a saber, uma política social disciplinar (condensada pela noção de workfare) e a diligente expansão do sistema penal (que batizei de prisonfare), sem esquecer a alegoria da responsabilidade individual que faz as vezes de cola cultural, unindo esses três componentes mencionados (WAQUANT, 2014, p. 143, grifos nossos). 
No seu principal campo de pesquisa, os EUA, Wacquant (2013) identificou que associado à crise do Estado de providência houve a erupção do Estado penal que reverberou com implicações práticas e ideológicas em outras sociedades submetidas às reformas neoliberais. A guerra ao crime dos EUA (nas últimas três décadas) tornou-se referência aos governos do primeiro mundo (nos últimos doze anos na Europa), inspirando o endurecimento da penalidade que levou ao inchamento espetacular da população carcerária. Os EUA serviram de exemplo para mostrar que "é possivel fazer recuar a delinquência real e o sentimento de insegurança subjetivo' por meio da ativação de políticas policiais, judiciárias e penitenciárias zelosas, focadas nas categorias marginais encontradas nas falhas e nos fossos da nova paisagem econômica" (WACQUANT, 2013, p. 13).

Nas suas pesquisas, Wacquant (2013) identificou nas prisões estadunidenses que os indivíduos encarcerados são principalmente pessoas de má reputação, doentes mentais, toxicômanos ou imigrantes ilegais e suas condenações foram mais pelo seu caráter ofensivo do que pela gravidade dos crimes. Essa gestão policial e carcerária confirma esse estatuto e “o encarceramento serve, antes de tudo, para regular, se não perpetuar, a pobreza e para armazenar os dejetos humanos do mercado" (WACQUANT, 2013, p. 126-7, grifo nosso). Essa política de criminalização da pobreza funciona de duas formas:

[...] reorganizar os serviços sociais em instrumentos de vigilância e controle das categorias indóceis à nova ordem econômica e moral. [...] o beneficiário deve aceitar qualquer emprego ou atividade semelhante que lhe for proposta, quaisquer que sejam a remuneração e as condições de trabalho, sob pena de ter que abrir mão do seu direito à assistência (workfare). Outras moldam a ajuda às famílias em função da assiduidade escolar de seus filhos ou do adolescente beneficiário (learnfare) ou da inscrição deles em pseudoprogramas de treinamento, que oferecem poucas ou mesmo nenhuma qualificação e perspectiva de emprego (WACQUANT, 2013, p. 111). O segundo componente da política de contenção repressiva dos pobres é o recurso maciço e sistemático à prisão [...]. O confinamento é a outra técnica a partir da qual o incomodo problema da marginalidade persistente, enraizada no desemprego, no 
subemprego e no trabalho precário, tornou-se menos visivel [...] (WACQUANT, 2013, p. 113).

Como fica evidenciado nessas passagens, Wacquant não reduz o neoliberalismo ao que chama de "império nu do mercado". Reconhecemos a originalidade das análises sobre a ascensão da face penal-punitiva do Estado associada às transformações nas politicas sociais e precarização do trabalho, porém identificamos que, no plano econômico, ele identifica o neoliberalismo com a "doutrina do laissez faire et laissez-passer".

Ainda que suas pesquisas tomem como base a realidade estadunidense e de alguns países europeus para construir suas teses sobre o Estado e as políticas punitivo-penais, não é dificil averiguar que esses dois contextos servem de modelo ou mesmo exportam ideias e politicas públicas para países do Sul.

Ainda que alguns autores, como Lessa (2013) que define o Estado de Bem-Estar como um mito, e outros considerem que no Brasil não se pode encontrar uma período histórico que possamos caracterizar como Estado de Bem-Estar Social, uma série de normas e leis de proteção social resultou das lutas por direitos de grupos da sociedade brasileira, notadamente o direito do trabalho e as garantias estabelecidas na Constituição de 1988. Estas normas vêm sendo alteradas profundamente, após o impeachment da Presidenta Dilma Rousseff, sobretudo as proteções aos trabalhadores, assim, tal como em outros países, a precarização do trabalho tem sido aprofundada. Vale lembrar que praticamente metade da população economicamente ativa no Brasil já se encontra em situação precária de trabalho, pois vive do trabalho informal.

De outro lado, temos no Brasil e em diversos países da América Latina uma guerra às drogas e à criminalidade que tem justificado o crescimento dos encarceramentos e um discurso de que a violência se resolve com prisões. Na prática, nossas prisões (sem condições mínimas de lotação e higiene) são depósitos dos segmentos marginalizados da classe trabalhadora, o principal alvo de uma das forças policiais que mais mata (e morre) no mundo. 
Essas características da realidade brasileira são indícios históricos que suportam a tese de Wacquant sobre o Estado punitivo como elemento genético do neoliberalismo, mas com diferentes matizes a depender do contexto. Isso nos lança o desafio imperioso de aprofundar as investigações sobre as consequências concretas e cotidianas das politicas neoliberais nesses países que não estão na origem das investigações de Wacquant.

Mesmo reconhecendo a potência da crítica de Wacquant, há que demarcar duas incoerências na sua análise do neoliberalismo. A primeira é traçar um paralelo do neoliberalismo com o liberalismo laissezferista e a outra é atribuir às políticas e ao Estado de Bem-Estar uma tábua de salvação do trabalhador, subjugando o caráter de classe e sua função de auxílio na exploração do capital sobre o trabalho em determinado momento histórico. Esses problemas podem ter decorrido da superficial apreciação que faz Wacquant das análises marxistas do neoliberalismo, como já apontamos sobre a interpretação que Wacquant faz dos estudos de Harvey. Isso implicou principalmente numa visão incompleta de Wacquant sobre as orientações econômicas relacionadas as bem identificadas implicações sociais do projeto neoliberal. Para colmatar essas lacunas e compreender os elementos de ordem econômica norteadores das transformações nas politicas sociais e do trabalho, buscamos as análises de Puello-Socarrás sobre as mudanças nas concepções teóricas e econômicas que norteiam o projeto neoliberal, ainda que ele não se restrinja a analisá-lo como projeto econômico.

\section{A concepção de homem empreendedor no programa de políticas neoliberais}

Para além da busca de um referencial que pudesse completar e corrigir as análises das concepções econômicas que consideramos inconsistentes em Wacquant, o que fundamenta a aproximação com o trabalho de Puello-Socarrás está relacionada a sua tese 7 sobre o neoliberalismo. Para Puello-Socarrás (2013b, p. 38-9), o neoliberalismo é 
Neoliberalismo como simbiose de políticas aparentemente contraditórias: as penais-punitivas e as de fomento ao empreendedorismo | Rodrigo Gameiro Guimarães e Rosimeri Carvalho da Silva

radicalmente autoritário, pois surge historicamente num arco autoritário de violência e terrorismo estatal e de processos para-legais pela mão da impunidade, é só considerar as ditaduras civico-militares espalhadas pela América Latina desde a década de 70. Ao ponto que, a contrarrevolução neoliberal mantém uma combinação de violência institucional e parainstitucional ${ }^{11}$. No entanto, essa tese é direcionada a caracterizar o momento de fundação neoliberal em regimes políticos autoritários, diferente do mostrado em Wacquant quando analisa o aspecto autoritário e atrofia do braço penal-punitivo e suas politicas para tratar isso como uma transformação genética do Estado que a princípio está acontecendo sob regimes democráticos liberais contemporâneos.

Outro ponto de conexão entre as políticas punitivo-penais (Wacquant) e a concepção de incentivo/garantia ao empreendimento (Puello-Socarrás) está em Harvey (2013, p. 75). Ele define que tem a função de "[...] favorecer fortes direitos individuais à propriedade privada, o regime de direito e as instituições de mercados de livre funcionamento e do livre comércio. [...] As empresas privadas e a iniciativa dos empreendedores são julgadas as chaves da inovação e da criação de riqueza.” Inclusive, o Estado pode, além disso, usar os aparatos de defesa, de polícia e as leis, ou até a força, para garantir o funcionamento dos mercados, logo pode "intervir, por vezes repressivamente, negando assim as próprias liberdades de que se supõe ser o garantidor" (HARVEY, 2013, p. 80).

Com Harvey podemos corrigir Wacquant. Fica claro que para Harvey (2013), o neoliberalismo na prática não se confunde com os princípios teóricos da economia neoclássica, nem põe o Estado como antagônico ao mercado ou tem seu início com o fim das políticas econômicas keynesianas, como caracterizou Wacquant. Aliás, Harvey (2013) considera que o período guiado por políticas keynesianas e pelo Estado de Bem-Estar é caracterizado

\footnotetext{
${ }^{11}$ Cita o exemplo do Paramilitarismo na Colômbia, associado com setores do Estado e da direção política, assim como práticas ecocidas autorizadas por Estados extrativistas e neoextrativistas (PUELLO-SOCARRAS, 2013b, p.40-1). Algumas obras de ficção como filmes, livros etc. e reportagens vinculam diretamente a violência nas comunidades periféricas de cidades como Rio de Janeiro pela relação orgânica estabelecida entre criminosos e políticos.
} 
Neoliberalismo como simbiose de políticas aparentemente contraditórias: as penais-punitivas e as de fomento ao empreendedorismo | Rodrigo Gameiro Guimarães e Rosimeri Carvalho da Silva

como liberalismo embutido ${ }^{12}$. Tal visão, sobre o período anterior ao neoliberalismo, confronta o entendimento de Wacquant sobre as politicas neoliberais como homônimas de laissez-faire e a ausência na sua crítica de tomar as politicas e Estados de Bem-Estar como importantes ferramentas da acumulação do capital.

Esse viés da análise de Wacquant sobre as politicas sociais, talvez nos levasse a caracterizar as politicas do Partido dos Trabalhadores (PT), no início dos anos 2000, até como anti-neoliberais. Há várias justificativas para isso. A mais óbvia é que a coligação petista defendia a retomada do protagonismo do Estado e das políticas públicas no projeto de desenvolvimento nacional, além, por exemplo, do aprofundamento das políticas sociais e ampliação dos serviços públicos. Foi também nesse governo que houve melhoria no padrão de renda e consumo da classe trabalhadora, vinculada ao aumento real do salário mínimo.

No entanto, a concentração de riqueza e desigualdade foram mantidas quase que inalteradas. Foram criadas politicas focalizadas ou compensatórias para enfrentar a pobreza, mas parte importante da renda que financiou esse protagonismo do Estado na economia e nos programas sociais foi proveniente da destruição e exploração de recursos naturais em quase toda América Latina, legitimando os planos extrativistas e o sacrificio da natureza pelo discurso da manutenção de postos de emprego e combate à pobreza (MOTA, AMARAL e PERUZZO, 2012, p. 162). Dessa forma, "emerge, sob o signo do novo-desenvolvimentismo, a ideologia do autoemprego, do empreendedorismo, dos negócios próprios, da necessidade de acumular um capital social robusto" (MOTA, AMARAL e PERUZZO, 2012, p. 167).

\footnotetext{
12 Depois da $2^{\text {a }}$ guerra, diversos países envolvidos tinham em comum Estados focados em alcançar pleno emprego, crescimento econômico e bem-estar dos seus cidadãos, para isso foram implementadas políticas fiscais e monetárias keynesianas. Os Estados também intervieram na política industrial e estabeleceram padrões de salário social e uma variedade de sistemas de bem-estar. Esse modelo é normalmente chamado de liberalismo embutido "para sinalizar como os processos de mercado e as atividades empreendedoras e corporativas vieram a ser circundados por uma rede de restrições sociais e políticas e um ambiente regulatório que às vezes restringiu, mas em outros casos liderou a estratégia econômica e industrial. [...]" (HARVEY, 2013, p. 20-1).
} 
Neoliberalismo como simbiose de políticas aparentemente contraditórias: as penais-punitivas e as de fomento ao empreendedorismo | Rodrigo Gameiro Guimarães e Rosimeri Carvalho da Silva

Esse conjunto de políticas, aparentemente contraditórias, gera muitos questionamentos, pois mescla, no mesmo programa, politicas de proteção social com outras de precarização do trabalho e incentivo ao empreendimento, por exemplo, e até recrudescimento das práticas penais e de encarceramento. O que suscitou, a partir das ideias de Puello-Socarrás, novos questionamentos. Seriam essas políticas respostas às crises e críticas ao projeto neoliberal dos anos 90? São experimentos para um neoliberalismo renovado?

Para Puello-Socarrás (2008a) sim, pois o neoliberalismo passa por um processo de renovação, caracterizado pelo giro nas referências das teorias econômicas que o fundamentam, que servem para responder às recentes crises nos anos 90 cuja implementação contribuiu para provocar. Isso não implica dizer que o neoliberalismo, em si, está em crise (PUELLOSOCARRÁS, 2008a). Aliás, a composição teórica que fundamenta o pensamento neoliberal não é unidade monolítica, mas um conjunto de disputas em que convergem as discrepâncias acadêmicas de diversas correntes intelectuais. Por exemplo, neoclássicos e keynesianos são normalmente considerados de escolas rivais, principalmente, porque os primeiros, facilmente rotulados de neoliberais, defendem teoricamente menos intervenção do Estado no mercado do que os keynesianos que, por estarem associados às políticas de bem-estar, foram criticados pelos neoliberais.

No entanto, Puello-Socorrás (2008a) considera que essas escolas são rivais só na aparência, não há uma contradição entre keynesianos e neoclássicos, pois não se desfazem do núcleo liberal que os vincula, ainda que expressem duas formas de levantar a capacidade governamental do Estado frente aos desafios pós-industriais. Logo, não constituem duas definições diferentes de Estado, apenas configuram distintos graus de liberalismo cuja variação está no entendimento sobre a intensidade das obrigações do Estado em prol do mercado. Aceitar a dicotomia neoliberalismo "anti-estatal" e keynesianos "pró-estatal" seria admitir que na fase de acumulação guiada pelas politicas de Welfare State, a ideologia 
Neoliberalismo como simbiose de políticas aparentemente contraditórias: as penais-punitivas e as de fomento ao empreendedorismo | Rodrigo Gameiro Guimarães e Rosimeri Carvalho da Silva

dominante não teve como objetivo central a defesa do mercado. Ainda que no keynesianismo essa defesa tenha ocorrido mediante ativos produtivos, financeiros, comerciais e administrativos estatais e pela intervenção na distribuição da renda pelos impostos, geração de emprego e provisão de serviços públicos, a orientação era ampliar a extensão do mercado e evitar as crises cíclicas do sistema capitalista.

Puello-Socorrás (2008a) também adverte que não se pode reduzir o universo neoclássico à sua ortodoxia do século $\mathrm{XX}$, pois seria restringir o neoliberalismo aos Estados Unidos, apesar de não incorreta, é uma visão reducionista da renovação liberal (PUELLO-SOCARRÁS, 2008a). A renovação do neoliberalismo é caracterizada por uma 'transição interna' consolidada nos deslocamentos teóricos que retiram a centralidade das escolas ortodoxas anglo-americanas para privilegiar correntes heterodoxas em que predominam referentes austriacos (americanos), mas não há exclusivamente eles. As fontes ideológicas desse pensamento heterodoxo são: a) as teorias austríacas com o desenvolvimento das teorias do empreendimento, b) os economistas alemães, Ordo-Liberais e a Escola Social de Mercado, defendendo que o mercado livre precisa de um Estado forte e c) as Sínteses Teóricas conhecidas como neoclássico-keynesianas (as duas neoclássicokeynesianas, chamadas de keynesianismo sem Keynes, e as outras duas Austro-americana e Americano-autriaca), posteriormente aprofundadas com as variantes austro-americanas (por exemplo, Elinor Ostrom) e americanoaustríacas (por exemplo, Douglass North). Puello-Socarrás adverte que essa mudança acontece no interior do neoliberalismo e não é simplesmente uma virada para as correntes austriacas, pois o neoliberalismo se alimenta de todo o seu arsenal ideológico. Esse trânsito, segundo ele, é tão somente para identificar uma tendência, pois o neoliberalismo funciona como uma totalidade, combinando as correntes ortodoxa e heterodoxa, mesmo quando se destacam mais recentemente em intensidade as correntes heterodoxas. 

fomento ao empreendedorismo | Rodrigo Gameiro Guimarães e Rosimeri Carvalho da Silva

Em correspondência com as duas escolas Neoclássicas, a Escola Anglo-Americana ${ }^{13}$ e a Escola Neoclássica Austriaca ${ }^{14}$, Puello-Socarrás (2013) distingue dois tipos de neoliberalismo: uma primeira versão (mais influenciada pela anglo-americana) e outra renovada (mais impregnada das ideias austro-americanas). A primeira inspirou as reformas (de Estado) estruturais e os ajustes (fiscais) de primeira geração, já as recentes contrarreformas em nível global de $2^{\mathrm{a}}$ e $3^{\mathrm{a}}$ geração sugerem um novo neoliberalismo, em que os núcleos econômicos austríaco e alemão são mais relevantes. Na questão estatal, as primeiras reformas eram anti-estatistas, voltadas ao Estado mínimo, no novo admite-se regulação (oportunista) do Estado, ainda que ambas sejam anti-intervencionistas (PUELLOSOCARRÁS, 2008a; 2013). Mesmo que abstratamente essas escolas pareçam opostas, "ambas compartilham dos principios gerais do liberalismo contemporâneo" (PUELLO-SOCARRÁS, 2008a, p. 69).

O trânsito no interior do neoliberalismo ocorre de sua versão ortodoxa (anglo-americana) para a versão austro-americana. A primeira está assentada na visão restrita à escolha racional e maximização (paradigma da simplicidade e estritamente econômico), engenharia social, modelos de concorrência perfeita e equilíbrio, ou seja, da teoria econômica fundada no homem econômico, indivíduo racional e calculador. A versão austro-americana manifesta suas críticas (superficiais) e abandona relativamente as categorias em torno do homo economicus para se basear no paradigma da complexidade e ativar noções mais funcionais, como homem empreendedor (homo redemptoris, empresário criativo), empreendimento e racionalidade criativa. Ela também inclui novas formas de ação institucional (privatizações implícitas nas alianças público-privadas e quase-mercados) (PUELLO-SOCARRÁS, 2008a; 2013). Os economistas austríacos definiram “[...] em torno do homem empreendedor o princípio antropológico por excelência do ser humano e do empreendimento como força ontológica

\footnotetext{
13 Escola marginalista, Marshallianos, Monetaristas e a síntese americano-austríaca do Novo Institucionalismo Econômico de North.

14 Desdobramento da Economia política de Böhm-Bawerk e Wieser, depois Hayek, Mises e Schumpeter e a sintese austro-americana.
} 
constitutiva do processo de mercado" (PUELLO-SOCARRÁS, 2008a, p. 86). Algo que Foucault já havia identificado, o empreendedor como um desdobramento do homem econômico, não em sentido puro (PUELLOSOCARRÁS, 2008a).

Nesse sentido, o princípio antropológico neoliberal é o homem empreendedor, ao qual as correntes ortodoxas anglo-americanas compreendem, segundo Puello-Socarrás como um atraso face ao homo oeconomicus, princípio antropológico do Liberalismo Clássico. Ele reforça que o neoliberalismo não é uma teoria econômica, mas se constitui nas suas diversas expressões, inclusive ideológica, é uma teoria social, ou seja, uma teoria sobre a ação humana. Ainda que seja possivel explicar suas fontes pela teoria econômica, conformando uma das suas manifestações. Assim, para Puello-Socarrás (2008a, p. 92) essas teorias austríacas estariam criando "a dimensão aparentemente nova e emergente que superaria a relação dicotômica típica, “capital-trabalho" ao diferenciar o sujeito capitalista e a especificidade do indivíduo empreendedor do sistema econômico. Nessas teorias, os empreendedores são os agentes que assumem os riscos e combinam os fatores de produção para criar inovação, enquanto os capitalistas proporcionam os meios de produção como proprietários de capital. Por outro lado, os empreendedores não seriam precisamente trabalhadores porque não dependem estritamente da venda da sua força de trabalho, então se constituiriam como mediadores que criam novas combinações de trabalho e capital ou um terceiro fator, inevitável à dinâmica capitalista, o insumo empreendedor (PUELLO-SOCARRÁS, 2008a).

Como os empreendedores não seriam somente proprietários do capital, mas precisariam adquirir certos meios de produção, pois, segundo Puello-Socarrás (2008a), o empreendedor é o empresário de si mesmo e a fonte de seus próprios rendimentos, as teorias do empreendimento preconizam um reforço sobre a necessidade de um mercado de capitais sadio e acessivel ao empreendedor. O crédito torna-se um dos principais 
focos da política econômica, como também de política social porque viabiliza os empreendedores entre trabalhadores pobres e informais (SOEDERBERG, 2014), assim como facilita o consumo das famílias de baixa renda. Montarse-ia um círculo virtuoso de uma economia baseada nos pilares do endividamento para o consumo e para o empreender.

\section{É fato que Reformas e políticas públicas orientadas por esse} referencial têm produzido transformações na economia real e do trabalho, pois estendem as relações de produção ou (re)incorporam à esfera de valor capitalista as atividades não mercantis (como trabalho doméstico e serviços públicos estatais). Também incentivam a flexibilização do trabalho e o crescimento dos trabalhadores por conta própria, fórmulas que redefinem a precarização social pela revalorização do 'auto-emprego' e da retórica da 'iniciativa empresarial' (exitosa), reforçando as teses do empreendimento. Esses fenômenos não podem ser reduzidos a mudanças tecnológicas ou em modalidades de contratos ou regulações do trabalho, pois implicam uma nova definição de emprego e de desemprego (PUELLO-SOCARRÁS, 2008a, p. 93), inclusive naturalizando as condições precárias e as diversas relações informais de trabalho que ocorrem nos processos de terceirização e subcontratação com tais empreendedores.

Essas concepções refletem uma visão, desde o mercado, que diminui temas como os direitos sociais, estabilidade no emprego, seguridade social, temas que eram essenciais por uma visão formulada do Estado, como por exemplo sob uma concepção de Welfare State defendem-se empregos de qualidade para gerar menos pressão sobre o gasto público, essa preocupação é desprezada no Workfare State. "Não sem razão, o 'Estado de Trabalho' se denomina 'Schumpeteriano"' (PUELLO-SOCARRÁS, 2008a, p. 96-7).

$\mathrm{Na}$ perspectiva de Arienti (2002), as politicas schumpeterianas visam o lado da oferta para promover a ampliação da capacidade inovativa das empresas e fundir isso nas cadeias de produção. Em relação à reprodução da força de trabalho muda-se para uma visão mais produtivista e preocupada com a competitividade do regime de disciplinamento para o trabalho (workfare). A ênfase da política é, além de fornecer mais 
qualificação aos trabalhadores, proporcionar mais flexibilidade e menos custos às empresas, subordinando mais a política social às demandas empresariais por mais flexibilidade da força de trabalho, bem como a flexibilização nos custos indiretos de mão-de-obra com as reformas trabalhista e previdenciária (ARIENTI, 2002, p. 20).

Como visto, é possivel aproximar a construção teórica de PuelloSocarrás do novo neoliberalismo com o regime workfare indicado por Wacquant, mas considerar que o homem empreendedor é principio antropológico do neoliberalismo e elemento genético do programa de políticas neoliberais amplia ainda as possibilidades de análises. Além disso, qualifica a tese de Wacquant sobre a responsabilização individual como o resgate de um principio liberal, sob a roupagem neoliberal do homem empreendedor. Desse modo, as teorias e ideias que respaldam a renovação do neoliberalismo qualificam a visão simplificada de Wacquant a respeito das transformações nas politicas econômicas que impactam o modo de sobrevivência econômica dos trabalhadores.

\section{A simbiose no programa neoliberal: liberdade de empreender e vigilância das políticas punitivo-penais}

A inspiração para o argumento deste texto surgiu do estudo das críticas do neoliberalismo formuladas por Wacquant e por Puello-Socarrás. Foi a partir deles que começamos a nos aproximar dos trabalhos que tomam o neoliberalismo como objeto de análise. Com isso, conseguimos identificar que cada um deles foca num aspecto do programa neoliberal, Wacquant no desenho do Estado e nas consequências sociais das politicas neoliberais enquanto Puello-Socarrás centra-se mais no desenho politico-econômico do neoliberalismo. Juntando isso com nossas inquietações de compreensão do nosso contexto, propusemos a articulação entre as duas abordagens, a partir da formulação de um argumento que se propõe a refletir sobre como a articulação entre essas duas perspectivas por entender que, postas em relação no mesmo argumento, elas proporcionam um indicativo de análise 
Neoliberalismo como simbiose de políticas aparentemente contraditórias: as penais-punitivas e as de fomento ao empreendedorismo | Rodrigo Gameiro Guimarães e Rosimeri Carvalho da Silva

de duas característica genéticas e aparentemente contraditórias do neoliberalismo. Adotamos a forma estilística de ensaio pela liberdade que ela nos oferece para realizar elucubrações, sem almejar uma construção fechada ou que se utiliza da história, como sugere Meneghetti (2011).

Apesar disso, reconhecemos que as abordagens que propomos aproximar partem de diferentes contextos de reflexão e, também por isso, dão ênfase a aspectos distintos quando tomam o neoliberalismo como objeto. Isso poderia levar o leitor a pensar que não é coerente ou mesmo possível realizar tal aproximação. No entanto, quando analisamos o neoliberalismo na realidade concreta vemos que os distintos elementos destacados por ambos (Wacquant e Puello-Socarrás) estão urdidos por uma teia relacional. Mais do que isso, ousamos argumentar que essas politicas, originadas em características genéticas do neoliberalismo, se relacionam simbioticamente, por isso não merecem ser analisadas separadamente.

Além da ampliação do potencial de crítica ao neoliberalismo que permite a articulação das duas abordagens num mesmo argumento, os limites e lacunas de cada uma também ficam mais evidentes ao relacionálas. No caso de Wacquant, como tratado em detalhes anteriormente, ficaram claros o pouco destaque e até equívocos na compreensão das abordagens econômicas norteadoras do projeto neoliberal, ainda que o seu foco seja nas consequências sociais desse projeto. A suplantação disso se deu com apoio no trabalho de Puello-Socarrás que centra sua discussão nas abordagens econômicas. A centralidade que o homo redemptoris (empreendedor) aufere na teoria econômica neoliberal explica como o reforço à responsabilização individual, percebido por Wacquant na análise das transformações nas politicas sociais e de trabalho, é naturalizado e chega aos programas de politicas, definindo toda uma antropologia econômica neoliberal.

Ao articular essas duas visões críticas ao neoliberalismo, identificamos outro limite em torno da definição de Estado-Centauro, elaborada por Wacquant. Simplificadamente, ele define-o com uma cabeça liberal que favorece os dominantes, montada num corpo autoritário que pune os dominados. Ao refletir sobre o contexto e considerar a análise de 
Puello-Socarrás das teorias econômicas que respaldam o programa neoliberal, entendemos que esse lado liberal não é "laissez faire et laisez passer", como diz Wacquant, pois verificamos uma série de correntes econômicas que, longe de orientar políticas desse tipo, orientam políticas de beneficios as empresas (com isenções, taxas de juros subsidiadas, financiamento da demanda etc.), não só assegurando a acumulação dos grandes capitalistas, mas estimulando os pequenos empreendimentos como alternativa ao emprego formal. Aliás, cunhamos o conceito de entrepreneurfare justamente para explicar o quanto o Estado, sob esse programa neoliberal, vem implementando políticas de construção ou reconfiguração de mercado, inclusive sob a aparente justificativa de estar garantindo direitos e prestando serviços sociais.

É impossivel não reconhecer o valor da descoberta e da construção teórica de Wacquant sobre como o Estado neoliberal aos dominados apresenta o corpo paternalista e punitivo (prisonfare), como se vê na escalada do encarceramento e substituição das políticas de bem-estar por políticas de disciplinamento para o trabalho (workfare) pelo mundo. Mais ainda, lembrar que mais do que as outras críticas ao neoliberalismo, Wacquant analisa como o lado penal-punitivo das politicas e do Estado se ampliam e consolidam num contexto e em países com alto nível de renda e governados em regime democráticos, ainda que de inclinação burguesa.

Isso nos permitiu analisar que as políticas de incentivo ao empreendimento individual (e auto-emprego) postas como alternativa de geração de renda dos trabalhadores, mais enfatizadas no trabalho de PuelloSocarrás, geram uma aparência de que as políticas públicas do Estado neoliberal produzem a liberdade individual, sugerindo que essas politicas seriam uma espécie de contrapartida (às críticas) ao braço autoritário do Estado e das políticas neoliberais. No entanto, assim como a obrigação de trabalhar ou se qualificar (workfare) para receber alguma proteção ou benefícios das políticas sociais, o empreender é a principal 
alternativa de sobrevivência posta ao trabalhador desempregado ou em situação de informalidade, naturalizando a responsabilidade individual pela sobrevivência e colocando-a como uma condição humana para viver em liberdade.

Em detrimento do esvaziamento da noção de trabalhador já substituída pelo conceito de pobre nas políticas públicas, há a disseminação dessa concepção do indivíduo empreendedor, que é justificada pela possibilidade de liberação de potencialidades e ampliação da liberdade, mas que vela a contradição de que sob o neoliberalismo houve um recrudescimento e multiplicação das políticas de controle disfarçadas em políticas de empregabilidade, de endividamento e até de segurança que justificam o crescimento do encarceramento e punição. Isso nos leva a definir o neoliberalismo como um estágio de profunda crise do capitalismo e ao mesmo tempo um projeto para mediar as graves contradições do sistema. Ao invés de ampliar as liberdades, tal como definido nas teorias que se fundamentam em principios liberais (do livre mercado e iniciativa) ou defendem a inovação e o empreendedorismo, o neoliberalismo funda-se como um regime de controle ampliado das liberdades principalmente das camadas pobres e marginalizadas da sociedade, como defende Wacquant.

Tal constatação foi possivel ao relacionar as análises de PuelloSocarrás - de que as teorias do empreendimento redesenharam as politicas econômicas e estão relacionadas às politicas sociais de disciplinamento para o trabalho - com o diagnóstico de Wacquant sobre as consequências das transformações dessas políticas no cotidiano e na sua relação com políticas punitivo-penais. A análise perspicaz que fazem os autores nos permite desnudar o modo como as políticas discutidas se relacionam. Ou seja, nas respostas que o Estado, e os grupos a ele atrelados, vem construindo à atual e profunda crise do capitalismo, o processo de precarização é fundamental para o avanço dos objetivos das classes dirigentes. A promessa de empregos não pode mais se realizar, pois os direitos alcançados ao longo de décadas de luta dos trabalhadores ficaram na mira dos detentores de capital e seus representantes. Os trabalhadores destituidos da possibilidade de 
manutenção da sua vida são responsabilizados pela sua desdita e a atuação do Estado passa a ser o encarceramento. Porque esta é uma política de responsabilização? Porque trata os trabalhadores desempregados como responsáveis pela situação em que vivem. Ao mesmo tempo, as políticas de estímulo ao empreendedorismo aliam a isto um conteúdo ideológico forte, através de teorias e políticas propagadoras da ideia de que a autonomia e a liberdade seriam alcançadas pelos trabalhadores que empreendem (entrepreneurfare). A configuração que esta simbiose toma em um país como o Brasil necessita de uma reflexão específica, que pretendemos expor em texto futuro, pois o encarceramento aqui tem outra dimensão e a ele se somam, neste seu momento histórico, atos de uma gravidade inesperada.

Com isso, foi possivel relacionar que a precarização das condições de vida do trabalhador tanto está contida pelas políticas punitivo-penais como é encoberta por teorias e políticas propagadoras da ideia de que a autonomia e a liberdade do ser humano seria alcançada pelo trabalhador na condição de empreendedor (entrepreneurfare), configurando a relação simbiótica entre

\section{as políticas punitivas e as do empreendimento.}

As políticas de entrepreneurfare são uma resposta do projeto neoliberal às crises provocadas nas reformas do welfare, e complementam as politicas de disciplinamento para o trabalho (workfare), além de naturalizar a informalidade e a precarização do trabalho. Essas políticas, ao redefinir o trabalhador como um empreendedor e pseudocapitalista, tentam abrandar os conflitos capital-trabalho e desarmar as oposições à intensificação da exploração do capital sobre o trabalho. Pelo fomento ao empreendimento, tais politicas constroem a quimera de liberdade do projeto neoliberal para desvinculá-lo das consequências sociais (desigualdade, pobreza e marginalização) da sua implementação e do braço penal-punitivo (prisonfare) do Estado neoliberal cuja ampliação aconteceu para lidar com esses problemas. Isso demonstra, como argumentado ao longo deste texto, que o projeto neoliberal relaciona simbioticamente as políticas de fomento ao 
Neoliberalismo como simbiose de políticas aparentemente contraditórias: as penais-punitivas e as de fomento ao empreendedorismo | Rodrigo Gameiro Guimarães e Rosimeri Carvalho da Silva empreendimento (entrepreneurfare) às políticas penais-punitivas que naturalizam o encarceramento dos trabalhadores pobres e marginalizados. 


\section{Referências}

ARIENTI, Wagner Leal. Uma análise regulacionista das reformas do estado capitalista: rumo ao estado pós-fordista?. Textos de Economia, Florianópolis, v. 8, n. 1, p. 1-36, jan. 2002.

BOURDIEU, Pierre. Razões Práticas: sobre a teoria da ação. Campinas: Papirus, 1996.

Sobre o poder simbólico. In: BOURDIEU, Pierre. O Poder Simbólico. Trad. Fernando Tomaz. Rio de Janeiro: Bertrand Brasil, 2001, p.07-16.

As estruturas sociais da economia. Lisboa: Instituto Piaget, 2006.

Sobre o Estado. São Paulo: Companhia das Letras, 2014.

DARDOT, P.; LAVAL, C. A nova razão do mundo: ensaio sobre a sociedade neoliberal. 1.ed. São Paulo: Boitempo, 2016.

DUMÉNIL, Gérard; LEVY, Dominique. A crise do neoliberalismo. São Paulo: Boitempo, 2014.

LAVAL, Christian; DADOT, Pierre. La Nueva Razón Del Mundo ensaio sobre la sociedad neoliberal. Barcelona: Editorial Gedisa, 2013.

FOUCAULT, Michel. Nascimento da biopolitica: curso dado no Collège de France (1978-1979). São Paulo: Martins Fontes, 2008.

HARVEY, D. A produção capitalista do espaço. São Paulo: Annablume, 2005.

O Neoliberalismo: história e implicações. 4. ed. São Paulo: Edições Loyola, 2013.

LESSA, S. Capital e estado de bem estar: o caráter de classes das politicas públicas. São Paulo: Instituto Lukács, 2013.

MENEGHETTI, Francis Kanashiro. O que é um ensaio-teórico? Revista de Administração Contemporânea, v. 15, n. 2, p. 320-332, 2011.

MOTA, A.E; AMARAL, A.; PERRUZO, J. O novo-desenvolvimentismo e as politicas sociais na América Latina. In: MOTA, A.E. (Org.) Desenvolvimentismo e construção de hegemonia. São Paulo: Cortez, 2012, p. 153-178. 
PUELLO-SOCARRÁS, JF. Nueva Gramática del Neo-liberalismo. Itinerarios teóricos, trayectorias intelectuales, claves ideológicas. Bogotá: Universidad Nacional de Colombia, Facultad de Derecho, Ciencias Politicas y Sociales, 2008a. 166p.

. ¿¿Un Nuevo Neo-liberalismo? Emprendimiento y Nueva Administración de "lo público". Revista Administración \& Desarrollo (Bogotá: Escuela Superior de Administración Pública) No. 49, Primer Semestre, 2008b, p. 7 39.

"Del Homo OEconomicus al Homo Redemptoris. Emprendimiento y Nuevo Neo-liberalismo". Otra Economía. Revista Latinoamericana de Economía Social y Solidaria (Polvorines: RILESS) Vol. 4, No. 6. I semestre. 2010, p. 181-206.

. "Breve historia del anti-neoliberalismo. Economía política Anuario de Estudios Políticos Latinoamericanos, No. 1, Bogotá: Universidad Nacional de Colombia, Maestría en Estudios Políticos Latinoamericanos, 2013a, p. 167-186.

"Ocho tesis sobre el neoliberalismo (1973-2013)" In RAMÍREZ, Hernán, $\mathbf{O}$ neoliberalismo sul-americano em clave transnacional: enraizamento, apogeu e crise. São Leopoldo: Oikos - Unisinos., pp. 13-57. 2013b.

SOEDERBERG, S. Debtfare States and the Poverty Industry: Money, Discipline, and the Surplus Population. London and New York: Routledge/RIPE, 2014.

WACQUANT, L. As Prisões da Miséria. Rio de Janeiro: Zahar, 1999. (versão digitalizada em 2004)

Os condenados da cidade: estudos sobre marginalidade avançada. 2.ed.Rio de Janeiro: Revan; FASE, 2005.

Três etapas para uma antropologia histórica do neoliberalismo realmente existente. Caderno CRH, Salvador, v. 25, n. 66, p. 505-518, Set./Dez. 2012

Punir os pobre: a nova gestão da miséria nos Estados Unidos [A onda punitiva]. 3.ed. Rio de Janeiro: Revan, 2013.

Marginalidade, etnicidade e penalidade na cidade neoliberal: uma cartografia analítica. Tempo Social, revista de sociologia da USP, v. 26, n. 2, nov., 2014. 